\title{
Review on Molecular Typing Methods of Pathogens
}

\author{
Tiehao Lin, Liying Lin, Fan Zhang \\ Guangdong Institute for Food and Drug Control, Guangzhou, China \\ Email:1093509842@qq.com
}

Received 14 May 2014; revised 13 June 2014; accepted 11 July 2014

Copyright (C) 2014 by authors and Scientific Research Publishing Inc.

This work is licensed under the Creative Commons Attribution International License (CC BY).

http://creativecommons.org/licenses/by/4.0/

c) (i) Open Access

\begin{abstract}
This paper presents several common molecular typing methods, Pulsed-Field Gel Electrophoresis (PFGE), Restriction Fragment Length Polymorphisma (RFLP), Random Amplified Polymorphic DNA (RAPD), Automatic Ribotyping, rep-PCR, Multi-Locus Sequence Typing (MLST), in which the application and progress of molecular typing of pathgens for these methods are described. These methods played an important role in pathgens source tracking, knowing the source(s) of bacteria in pharmaceutical, preventing and controlling the diarrhea and food-poisoning outbreaks, which have great value in the remediation and prevention of further bacterial contamination.
\end{abstract}

\section{Keywords}

\section{Pathgens, Bacterial Typing Techniques, Pharmaceutical}

\section{Introduction}

Pathogens are a major pollutant of pharmaceutical according to many reports. Various sources contribute pathogens to contaminated pharmaceutical, including fecal pollution from humans, wildlife, and livestock. The presence of any fecal bacteria in pharmaceutical is considered as a health hazard. Knowing the source(s) of bacteria in pharmaceutical is of great value in the remediation and prevention of further bacterial contamination. Phenotypic methods and molecular-based techniques were used to determine the source of fecal pathogen contamination in environmental samples.

Phenotypic methods play an important role in identification of genus level. Serotyping, based on the Kauffmann-White scheme, remains the standard for classification of Salmonella isolates in outbreak investigations but now has been supplemented by a range of molecular genotyping methods [1] [2].

In recent years, molecular-based techniques, such as Pulsed-Field Gel Electrophoresis (PFGE), Restriction Fragment Length Polymorphisma (RFLP), Random Amplified Polymorphic DNA (RAPD), Automatic Ribo- 
typing, rep-PCR, Multi-Locus Sequence Typing (MLST) have been shown to be useful methods for discrimination among isolates of pathogens [3] [4].

\section{The Progress and Application of PFGE}

PFGE is a valuable tool for assessing pathogens interrelatedness. It is based on the study of total bacterial DNA restriction patterns, which was first developed by Schwartz and Cantor at Columbia University in 1984 [5]. It has made a tremendous impact in the field of molecular biology by making possible the separation of large DNA fragments. In conventional agarose gel electrophoresis, DNA molecules bigger than $40-50 \mathrm{~kb}$ in size fail to migrate efficiently and appear in the gel as a single large diffuse band due to their size-independent co-migration, known as reptation [6] [7]. By periodically applying changes in the direction of the electrical field in which large DNA molecules are suspended, PFGE allows the separation of DNA molecules over $1000 \mathrm{~kb}$.

Fujino found that the PFGE patterns of 56 Staphylococcus aureus isolates were classified into nine types: type A, its subtypes, A1 and A2, and types B through to G. And the predominant strain of methicillin-resistant $S$. aureus isolates in the pediatric ward was a certain strain that may be originated from the one clone [8].

In another case, Thirty eight strains of $V$. parahaemolyticus were isolated from seafood in Hebei province of China. These strains were typed by PFGE technique and 38 strains were grouped into 5 types with $71 \%$ pattern similarity. All the type E were isolated from Shijiazhuang, Baoding and Langfang and simultaneously resistant to ampicillin, sulfisoxazole, streptonigrin and vancomycin, suggesting a relationship between these strains. The data of antimicrobial susceptibility test and PFGE profiles in this study showed a good correlation among antimicrobial susceptibility test, PFGE profiles and geographic distribution.

Ji Hui-Ling indicated that the genomic DNA in different Salmonella strains was isolated and separated on PFGE after digesting with $X b a$ I. The electrophoresis patterns were analyzed using the Freeview software. DNA isolated from 13 strains was classified into 10 different subtypes according to the PFGE patterns. PFGE technique can be used for molecular typing of Salmonella subtypes and typing result is of stability [9].

Zhao Jin indicated that five PFGE patterns were found among 12 strains of S. typhimurium. The results of PFGE typing and molecular epidemiology indicated that the outbreaks of S. typhiurium caused by preserved egg occurred in Sichuan province in 2007. It is evident that PFGE typing, along with epidemiological data, can enhance the source-tracing of S. typhimurium and give early warning of food-borne diseases [10].

\section{The Progress and Application of RFLP}

The basic technique for detecting RFLPs involves fragmenting a sample of DNA by a restriction enzyme that can recognize and cut DNA wherever a specific short sequence occurs in a process known as a restriction digest. The resulting DNA fragments are then separated by length by agarose gel electrophoresis and transferred to a membrane via the Southern blot procedure. Hybridization of the membrane to a labeled DNA probe determines the length of the fragments that are complementary to the probe. A RFLP occurs when the length of a detected fragment varies between individuals. Each profile is considered an allele and can be used in genetic analysis.

RFLP was used by Suthienkul to analysis the molecular typing of $V$. parahaemolyticus. The TDH and TRH genes of $137 \mathrm{~V}$. parahaemolyticus were analyzed, which showed that $T D H$ can divide into 5 types while $T R H 4$ types after digestion by Hind III [11]. Another researcher used RFLP to distinguish two related species A. flavus and A. oryzae and to analyze their phylogenetic relationships [12].

Although, complex RFLP patterns can be difficult to interpret, RFLP remains a reproducible and high discriminatory system.

\section{The Progress and Application of RAPD}

Using random primers of approximately 10 bases, amplicons throughout the genome are targeted and amplified. Amplified products are subsequently separated on an agarose gel and stained with ethidium bromide. The genetic variation analysis based on RAPD allows proper genetic diversity due to its capacity to generate random markers from the entire genome.

Diaz-Guerra TM et al. have used RAPD with three primers (R-108, R-151 and AP12 h) for typing 11 A. flavus isolates and they have found a satisfactory discriminatory power [13]. And Hara Kudo et al. have used RAPD to analysis the molecular typing of $V$. parahaemolyticus. And the results indicated that most O3:K6 tdh- 
positive strains belonged to the pandemic 03:K6 clone and suggested that serovariation took place in the Japanese environment [14].

In another case, eighteen samples of the O3:K6 and O3:KUT serotypes of $V$. parahaemolyticus were analyzed by multiplex polymerase chain reaction (m-PCR) for detection of the $t l$, $t d h$ and $t r h$ genes, by RAPD using two primers, and by amplification of the rDNA 16S - 23S region. RAPD produced two amplification patterns allowing grouping two $t d h$-Kanagawa-negatives isolates [15].

Cetinkaya indicated that RAPD analysis revealed that this mini-MRSA outbreak was caused by contamination of surgical dressing container with MRSA and nasal MRSA carriage in ward staff. And RAPD seems to be a valuable typing method for analysis of nosocomial MRSA outbreaks because of its simplicity and rapidity [16].

\section{The Progress and Application of Ribotyping}

Ribotyping is a method that can identify and classify bacteria based upon differences in rRNA (16S and 23S rRNA). DNA is extracted from a colony of bacteria and then restricted into discrete-sized fragments. The DNA is then transferred to a membrane and probed with a region of the rRNA operon to receal the pattern of rRNA genes. The pattern is recorded, digitized and stored in a database. It is variations that exist among bacteria in both the position and intensity of rRNA bands that can be used for their classification and identification.

The Riboprinter carried out cell lysis, DNA digestion, gel electrophoresis, DNA transfer to a hybridization membrane, and Southern hybridization using a chemiluminescent ribosomal probe [17]. The resulting riboprint patterns were recorded and analyzed using the software supplied with the Riboprinter system. The riboprint pattern for each isolate was compared with the patterns produced for all other isolates using the same restriction enzyme. The sample number of the first pattern in each group became the label used to identify that group. The analysis software derived a single average pattern for each ribogroup, as well as information on the similarity between each pattern within the group and the group average pattern.

Gendel et al. reported the existence of at least 12 different ribotype patterns among O3:K6 strains from the United States and Asia by using three restriction enzymes, and they found that most of the strains from the 1998 Galveston Bay outbreak were different than those from New York or Asia [18].

Recently, the phenotypic and genotypic of $V$. parahaemolyticus in seawater and seaweed samples from three areas of Kii Channel, Japan during June 2003 to May 2004 were determined. Isolates were obtained by selective enrichment of samples and detection of by colony hybridization with a species-specific probe. Twenty and 17 serotypes were found among the selected seaweed and seawater isolates, respectively. Cluster analysis revealed 19, 11, 7 and 9 ribotypes during summer, autumn, winter and spring, respectively [19].

\section{The Progress and Application of REP-PCR}

ERIC and REP-PCR methods respectively utilize primers complementary to specific sequences in the bacterial genome. ERIC sequences are 126 bp long and appear to be restricted to transcribed regions of the genome; whereas the REP sequences consist of a highly conserved 33 bp inverted repeat sequence [20].

In recent years, REP-PCR technique has been used for the typing of $V$. parahaemolyticus, a 22-mer primer-specific enterobacterial repetitive intergenic consensus sequence (ERIC)-based PCR [21], variations in the sequence of the highly conserved ribosomal gene spacer (RS) sequence [22] and a 38-bp repetitive intergenic palindromic sequence [23].

Wong et al. evaluated three rapid PCR typing methods using primers designed on the basis of the following specific sequences: conserved ribosomal gene spacer sequence (RS), repetitive extragenic palindromic sequence (REP), and enterobacterial repetitive intergenic consensus sequence (ERIC). Forty domestic strains of V. parahaemolyticus, representing a wide range of PFGE patterns, were grouped into 15, 27, and 27 patterns, with discrimination indexes of $0.91,0.97$, and 0.98 , by RS-, REP-, and ERIC-PCR, respectively. The discriminative abilities of these PCR methods closely approached or even exceeded those of PFGE and ribotyping. REP-PCR is preferable to ERIC-PCR because of the greater reproducibility of its fingerprints, while RS-PCR may be a practical method because it generates fewer amplification bands and patterns than the alternatives [24].

Khan designed two PCR primers to specifically amplify the unique sequences from O3:K6 isolates, while the primers were tested with other Vibrio spp. and other closely related species and no amplification of the 327-bp PCR product was found. The PCR method can be used to specifically identify O3:K6 V. parahaemolyticus isolates in less than $6 \mathrm{~h}$ [25]. 


\section{The Progress and Application of MLST}

MLST was a DNA sequence-based method, which developed by Chan et al. and Maiden et al. [26] [27]. MLST is a highly discriminatory method of characterizing bacterial isolates on the basis of the sequences of 450-bp internal fragments of seven housekeeping genes [28]. For each gene fragment, the different sequences are assigned as distinct alleles, and each isolate is defined by the alleles at each of the seven housekeeping loci (the allelic profile or sequence type [ST]). As there are many alleles at each of seven loci, isolates are highly unlikely to have identical allelic profiles by chance, and isolates with the same allelic profile can be assigned as members of the same clone [29]. Sequence data are readily compared between laboratories and a major advantage of MLST is the ability to compare the results obtained in different studies via the Internet. In addition, the data obtained by MLST can be used to address basic questions about the evolutionary and population biology of bacterial species [29]. MLST provides unambiguous DNA sequence data that can be easily exchanged and compared via worldwide web databases, and combines PCR and automated DNA sequencing to reduce labor and analysis time, so provided discriminatory power comparable to or higher than that provided by fragment-based methods [27] [30].

In one case, nine housekeeping genes in L. monocytogenes were analyzed by MLST [31]. Most of these gene fragments showed relatively lower nucleotide polymorphism levels, e.g., abcZ (6.1\%), bglA (5.0\%), cat (7.8\%), dapE (8.3\%), ldh (4.3\%), IhkA (3.5\%), pgm (4.4\%), and sod (2.9\%). In addition, MLST was unable to differentiate epidemiologically unrelated strains, especially for the disease related serotype $4 \mathrm{~b}$ strains.

In another study, seven housekeeping genes (dnaE, gyrB, recA, $d t d S$, pntA, pyrC, thaA) in $V$. parahaemolyticus isolates, were analyzed by MLST, and the results were uploaded to the Public Database.

The sequences of internal fragments of seven housekeeping genes were obtained for $155 \mathrm{~S}$. aureus isolates from patients with community-acquired and hospital-acquired invasive disease in the Oxford, United Kingdom. Fifty-three different allelic profiles were identified, and 17 of these were represented by at least two isolates. The MLST scheme was highly discriminatory and was validated by showing that pairs of isolates with the same allelic profile produced very similar SmaI restriction fragment patterns by PFGE.

A concern with typing methods that rely on DNA sequence information, such as MLST, appear to be susceptible to the genetic mixing of populations as a consequence of frequent recombination and somewhat less frequent mutation [32] [33].

\section{Discussion}

In conclusion, PFGE has been successful for the detection of clusters that could represent outbreaks in a few instances and has been of use in outbreak investigations. However, the diversity of PFGE patterns is thought to limit the usefulness of PFGE for outbreak detection [34]. In addition to being highly discriminatory, perhaps too much so, we found novel data in this work that PFGE, on occasion, inappropriately groups Campylobacter isolates that appear to be genetically widely divergent by producing an indistinguishable banding pattern.

Both RAPD and ERIC-PCR, which were PCR-based methods, have a potential discriminative ability and can therefore be used as rapid methods for molecular epidemiological typing of pathogens. REP-PCR is inferior to RAPD and ERIC-PCR owing to the facts that it was less reproducible and yielded a relatively small number of products and ERIC-PCR was less reproducible and yielded a relatively smaller number of fingerprints compared to RAPD, while the major problem in RAPD typing is a lack of reproducibility of patterns (variation of number, size, and intensity of bands) [35] and the interlaboratory reproducibility.

Although, complex RFLP patterns can be difficult to interpret, RFLP remains a reproducible and high discriminatory system. This approach is generally suitable for discriminating among different species, but has insufficient discriminatory power to distinguish among unrelated isolates within a species. MLST provides a reliable predictor of clonality, and correlates closely with the results from multilocus enzyme electrophoresis, and has been considered relatively stable [36].

All typing methods were ultimately useful. The challenge is to find out what methods are useful for specific purposes. In this work, the application and progress of molecular typing of pathgens for these methods were described and evaluated. Furthermore, as has been seen in work by other researchers [37], the comparison of a number of methods has allowed the evaluation of the relative strengths and weaknesses of each method in grouping isolates within the bacteria in pharmaceutical. 


\section{References}

[1] Botteldoorn, N., Herman, L., Rijpens, N., et al. (2004) Phenotypic and Molecular Typing of Salmonella Strains Reveal Different Contamination Source in Two Commercial Pig Slaughterhouses. Applied and Environmental Microbiology, 70, 5305-5314. http://dx.doi.org/10.1128/AEM.70.9.5305-5314.2004

[2] Weigel, R.M., Qiaoa, B.Z., Teferedegneb, B., Suh, D.K., Barber, D.A., et al. (2004) Comparison of Pulsed Field Gel Electrophoresis and Repetitive Sequence Polymerase Chain Reaction as Genotyping Methods for Detection of Genetic Diversity and Inferring Transmission of Salmonella. Veterinary Microbiology, 100, 205-217. http://dx.doi.org/10.1016/j.vetmic.2004.02.009

[3] Tsen, H.Y. and Lin, J.S. (2001) Analysis of Salmonella Enteritidis Strains Isolated from Food-Poisoning Cases in Taiwan by Pulsed Field Gel Electrophoresis, Plasmid Profile and Phage Typing. Journal of Applied Microbiology, 91, 7279. http://dx.doi.org/10.1046/j.1365-2672.2001.01343.x

[4] Garaizar, J., López-Molina, N., Laconcha, I., Baggesen, D.L., Rementeria, A., Vivanco, A., et al. (2000) Suitability of PCR Fingerprinting, Infrequent-Restriction Site PCR, and Pulsed-Field Gel Electrophoresis, Combined with Computerized Gel Analysis, in Library Typing of Salmonella Enterica Serovar Enteriditis. Applied and Environmental Microbiology, 66, 5273-5281. http://dx.doi.org/10.1128/AEM.66.12.5273-5281.2000

[5] Schwartz, D.C. and Cantor, C.R. (1984) Separation of Yeast Chromosome-Sized DNAs by Pulsed Field Gradient Gel Electrophoresis. Cell, 37, 67-75. http://dx.doi.org/10.1016/0092-8674(84)90301-5

[6] Singh, A., Goering, R.V., Simjee, S., Foley, S.L. and Zervos, M.J. (2006) Application of Molecular Techniques to the Study of Hospital Infection. Clinical Microbiology Reviews, 19, 512-530. http://dx.doi.org/10.1128/CMR.00025-05

[7] Slater, G.W. (2009) DNA Gel Electrophoresis: The Reptation Model(s). Electrophoresis, 30, S181-S187. http://dx.doi.org/10.1002/elps.200900154

[8] Fujino, T., Mori, N., Kawana, A., et al. (2001) Molecular Epidemiology of Methicillin-Resistant Staphylococcus aureus in a Tokyo Hospital in 2001. Japanese Journal of Infectious Diseases, 54, 240-242.

[9] Ji, H.L., Cheng, Y., Liu, X.F., et al. (2005) Application of Pulsed Field Gel Electrophoresis in Molecular Typing of Salmonella Typhimurium. Strait Journal of Preventive Medicine, 1, 15-22.

[10] Zhao, J., Yang, X.R., Xu, Y.F., et al. (2007) PFGE-Typing of Salmonella Typhimurium Isolates for Source Identification in Sichuan Province, Journal of Preventive Medicine Information, 2009, 12.

[11] Suthienkul, O., Iida, T. and Park, K.S. (1996) Restriction Fragment Length Polymorphism of the tdh and trh Genes in Clinical Vibrio parahaemolyticus Strains. Journal of Clinical Microbiology, 34, 1293-1295.

[12] Klich, M.A., Yu, J., Chang, P.K., Mullaney, E.J., Bhatnagar, D. and Cleveland, T.E. (1995) Hybridization of Genes Involved in Aflatoxin Biosynthesis to DNA of Aflatoxigenic and Non-Aflatoxigenic Aspergilli. Applied Microbiology and Biotechnology, 44, 439-443. http://dx.doi.org/10.1007/BF00169941

[13] Diaz-Guerra, T.M., Mellado, E., Cuenca-Estrella, M., Gaztelurrutia, L., Navarro, J.I. and Tudela, J.L. (2000) Genetic Similarity among one Aspergillus flavus Strain Isolated from a Patient Who Underwent Heart Surgery and Two Environmental Strains Obtained from the Operating Room. Journal of Clinical Microbiology, 38, 2419-2422.

[14] Hara Kudo, Y., Sugiyama, K., Nishibuchi, M., et al. (2003) Prevalence of Pandemic Thermostable Direct Hemolysin Producing Vibrio parahaemolyticus O3:K6 in Seafood and the Coastal Environment in Japan. Applied and Environmental Microbiology, 69, 3883-3891. http://dx.doi.org/10.1128/AEM.69.7.3883-3891.2003

[15] Leal, N.C., da Silva, S.C., Cavalcanti, V.O., et al. (2008) Vibrio parahaemolyticus Serovar O3:K6 Gastroenteritis in Northeast Brazil. Journal of Applied Microbiology, 105, 691-697.

[16] Cetinkaya, Y., Kocagoz, S., Hayran, M., et al. (2000) Analysis of Minioutbreak of Methicillin-Resistant Staphylococcus aureus in a Surgical Ward by Using Arbitrarily Primed Polymerase Chain Reaction. Journal of Chemotherapy, 12, 138-144. http://dx.doi.org/10.1179/joc.2000.12.2.138

[17] Bruce, J. (1996) Automated System Rapidly Identifies and Characterizes Microorganisms in Food. Food Technology, 77, 77-81.

[18] Gendel, S.M., Ulaszek, J., Nishibuchi, M. and DePaola, A. (2001) Automated Ribotyping Differentiates Vibrio parahaemolyticus O3:K6 Strains Associated with the Texas Outbreak from other Clinical Strains. Journal of Food Protection, 64, 1617-1620.

[19] Mahmud, Z.H., Neogi, S.B., Kassu, A., Wada, T., Islam, M.S., Nair, G.B. and Ota, F. (2007) Seaweeds as a Reservoir for Diverse Vibrio parahaemolyticus Populations in Japan. International Journal of Food Microbiology, 118, 92-96. http://dx.doi.org/10.1016/j.ijfoodmicro.2007.05.009

[20] Versalovic, J., Koeuth, T. and Lupski, J.R. (1991) Distribution of Repetitive DNA Sequences in Eubacteria and Application to Fingerprinting of Bacterial Genomes. Nucleic Acids Research, 19, 6823-6831. http://dx.doi.org/10.1093/nar/19.24.6823 
[21] Marshall, S., Clark, C.G., Wang, G., Mulvey, M., Kelly, M.T. and Johnson, W.M. (1999) Comparison of Molecular Methods for Typing Vibrio parahaemolyticus. Journal of Clinical Microbiology, 37, 2473-2478.

[22] Stern, M.J., Ames, G.F.L., Smith, N.H., Robinson, E.C. and Higgins, C.F. (1984) Repetitive Extragenic Palindromic Sequences: A Major Component of the Bacterial Genome. Cell, 37, 1015-1026. http://dx.doi.org/10.1016/0092-8674(84)90436-7

[23] Wong, H.C., Liu, C.C., Pan, T.M., Wang, T.K., Lee, C.L. and Shih, D.Y.C. (1999) Molecular Typing of Vibrio arahaemolyticus Isolates, Obtained from Patients Involved in Food Poisoning Outbreaks in Taiwan, by Random Amplified Polymorphic DNA Analysis. Journal of Clinical Microbiology, 37, 1809-1812.

[24] Wong, H.C. and Lin, C.H. (2001) Evaluation of Typing of Vibrio parahaemolyticus by Three PCR Methods Using Specific Primers. Journal of Clinical Microbiology, 39, 4233-4240. http://dx.doi.org/10.1128/JCM.39.12.4233-4240.2001

[25] Khan, A.A., McCarthy, S., Wang, R.F., et al. (2002) Characterization of United States Outbreak Isolates of Vibrio parahaemolyticus Using Enterobacterial Repetitive Intergenic Consensus (ERIC) PCR and Development of a Rapid PCR Method for Detection of O3:K6 Isolates. FEMS Microbiology Letters, 206, 209-214. http://dx.doi.org/10.1111/j.1574-6968.2002.tb11011.x

[26] Chan, M., Maiden, M.C.J. and Spratt, B.G. (2001) Database-Driven Multi Locus Sequence Typing (MLST) of Bacterial Pathogens. Bioinformatics, 17, 1077-1083. http://dx.doi.org/10.1093/bioinformatics/17.11.1077

[27] Maiden, M.C.J., Bygraves, J.A., Feil, E., Morelli, G., et al. (1997) Multilocus Sequence Typing: A Portable Approach to the Identification of Clones within Populations of Pathogenic Microorganisms. Proceedings of the National Academy of Sciences of the United States of America, 95, 3140-3145. http://dx.doi.org/10.1073/pnas.95.6.3140

[28] Hunter, P.R. and Gaston, M.A. (1988) Numerical Index of the Discriminatory Ability of Typing Systems: An Application of Simpson's Index of Diversity. Journal of Clinical Microbiology, 26, 2465-2466.

[29] Thompson, R.J., Bouwer, H.G.A., Portnoy, D.A. and Frankel, F.R. (1998) Pathogenicity and Immunogenicity of a Listeria onocytogenes Strain that Requires D-Alanine for Growth. Infection and Immunity, 66, 3552-3561.

[30] Enright, M.C. and B.G. (1999) Spratt. Multilocus Sequence Typing. Trends in Microbiology, 7, 482-487. http://dx.doi.org/10.1016/S0966-842X(99)01609-1

[31] Salcedo, C., Arreaza, L., Alcala, B., De La Fuente, L. and Vazquez, J.A. (2003) Development of a Multilocus Sequence Typing Method for Analysis of Listeria monocytogenes Clones. Journal of Clinical Microbiology, 41, 757-762. http://dx.doi.org/10.1128/JCM.41.2.757-762.2003

[32] Schouls, L.M., Reulen, S., Duim, B., Wagenaar, J.A., Willems, R.J.L., Dingle, K.E., Colles, F.M. and Van Embden, J.D.A. (2003) Comparative Genotyping of Campylobacter jejuni by Amplified Fragment Length Polymorphism, Multilocus Sequence Typing, and Short Repeat Sequencing: Strain Diversity, Host Range, and Recombination. Journal of Clinical Microbiology, 41, 15-26. http://dx.doi.org/10.1128/JCM.41.1.15-26.2003

[33] Suerbaum, S., Lohrengel, M., Sonnevend, A., Ruberg, F. and Kist, M. (2001) Allelic Diversity and Recombination in Campylobacter jejuni. Journal of Bacteriology, 183, 2553-2559. http://dx.doi.org/10.1128/JB.183.8.2553-2559.2001

[34] Hedberg, C.W., Smith, K.E., Besser, J.M., Boxrud, D.J., Hennessy, T.W., Bender, J.B., Anderson, F.A. and Osterholm, M.T. (2001) Limitations of Pulsed-Field Gel Electrophoresis for the Routine Surveillance of Campylobacter Infections. Journal of Infectious Diseases, 184, 242-243. http://dx.doi.org/10.1086/322005

[35] Lin, D., Lehmann, P.F., Hamory, B.H., Padhye, A.A., Durry, E., Pinner, R.W. and Lasker, B.A. (1995) Comparison of Three Typing Methods for Clinical and Environmental Isolates of Aspergillus fumigatus. Journal of Clinical Microbiology, 33, 1596-1601.

[36] Dingle, K.E., Colles, F.M., Falush, D. and Maiden, M.C. (2005) Sequence Typing and Comparison of Population Biology of Campylobacter coli and Campylobacter jejuni. Journal of Clinical Microbiology, 43, 340-347. http://dx.doi.org/10.1128/JCM.43.1.340-347.2005

[37] Nielsen, E.M., Engberg, J., Fussing, V., Petersen, L., Brogren, C.H. and On, S.L. (2000) Evaluation of Phenotypic and Genotypic Methods for Subtyping Campylobacter jejuni Isolates from Humans, Poultry, and Cattle. Journal of Clinical Microbiology, 38, 3800-3810. 
Scientific Research Publishing (SCIRP) is one of the largest Open Access journal publishers. It is currently publishing more than 200 open access, online, peer-reviewed journals covering a wide range of academic disciplines. SCIRP serves the worldwide academic communities and contributes to the progress and application of science with its publication.

Other selected journals from SCIRP are listed as below. Submit your manuscript to us via either submit@scirp.org or Online Submission Portal.
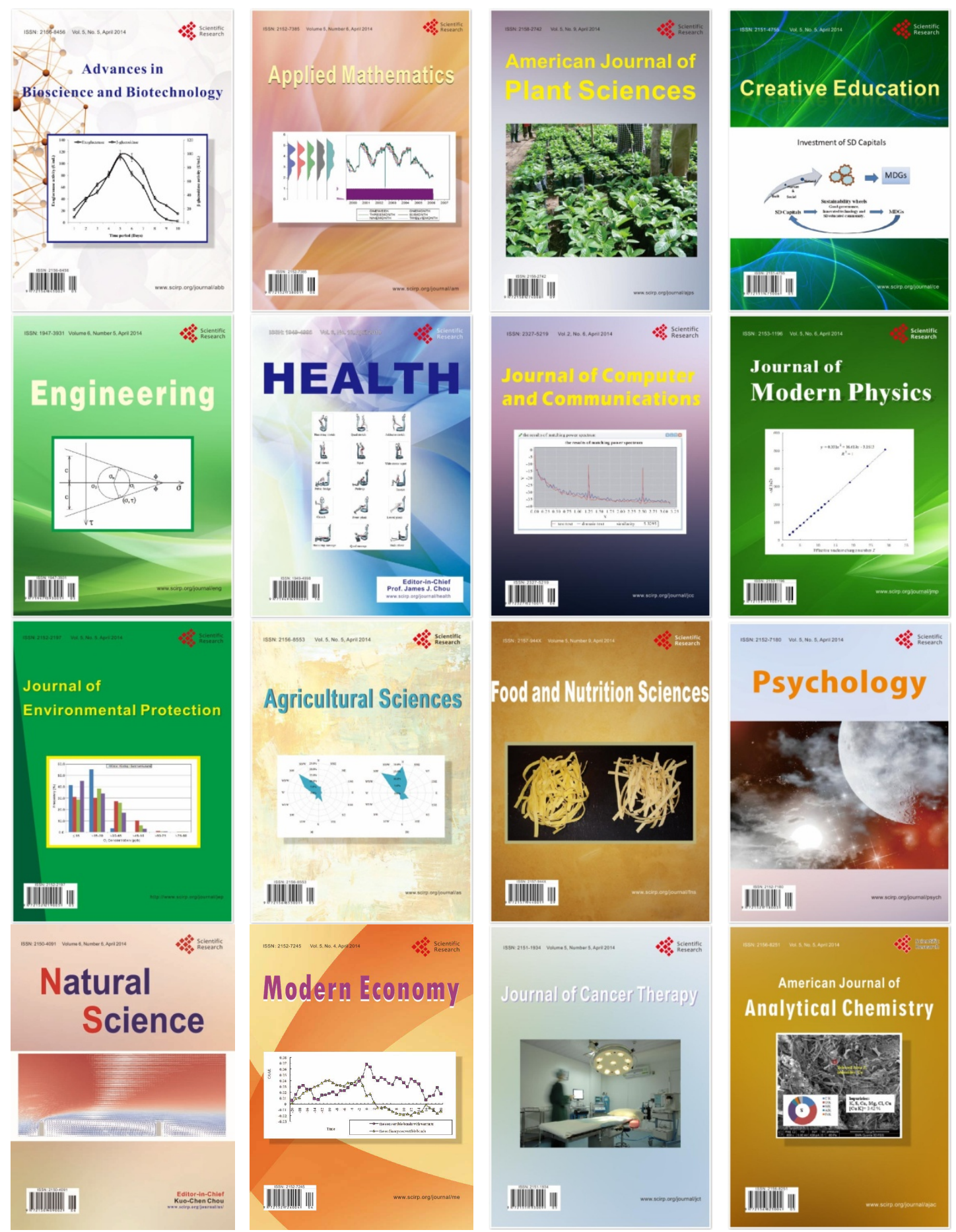